\title{
Misanian Men, are or aren't a Prostatic Adenocarcinoma?
}

\author{
Haider Saadoon Qasim Alhilfi ${ }^{*}$ \\ ${ }^{I}$ Department of Medicine, Faculty of Medicine, Misan University, Misan, 62061, Iraq
}

\begin{abstract}
It is an observational study in Al-Shafaa Oncology Center in Misan province about male patients with prostatic carcinoma to make an idea about the prevalence of this malignancy. This study was carried out during the period from July 2018 to March 2019 in Al-Shafaa Oncology Center in Al-Sadder teaching hospital in Misan province in which 53 male patients were involved. In our study we found that that the disease reaching a peak among patients between (70-80) years, (66.03\%) of patients are a smoker (13.2\%), had a family history of different type of cancer, (100\%) of the patients had adenocarcinoma, (56.6\%) that had high-grade cancer (Gleason score $\geq 8$ ), (77.35\%) of the patient had PSA level $>100 \mathrm{ng} / \mathrm{ml}$. The prostate cancer in Misan appears to be more likely to occur in the presence of particular risk factor like age, hypertension, family history, and less likely in the presence of diabetes mellitus. It is more likely to be presented with high grade and metastatic disease, and this may be primarily explained by the absence of the screening program.
\end{abstract}

Keywords: prostate cancer; adenocarcinoma; gleason score

\section{INTRODUCTION}

Prostate cancer is the second most encountered cancers in men, and globally in 2018, the new cases were $1,276,106$ men and led to 358,989 deaths worldwide (Bray et al., 2018). Adenocarcinoma accounts for more than 95\% besides other histopathology like squamous or transitional cells or, rarely, Carcino-sarcomas (Fitzmaurice et al., 2017). The incidence and mortality rates have significant discrepancies between countries and ethnicities. In developed countries in North America and Europe, it is common; however, it appears to be not as prevalent among developing countries in the middle east and north Africa (Fitzmaurice et al., 2017). Asian or African men who have lived all their lives in western countries have a high risk, and more than in white males of those countries, and this is maybe more closely related to environmental factors rather than racial or genetic factors (Fitzmaurice et al., 2017). Early-stage cancer is asymptomatic, but we may be seeing frequency, urgency, nocturia, and hesitancy, those are usually related to benign prostate hypertrophy (BPH) (Kimura et al., 2016). FDA at 1994 approved PSA testing for early detection of prostate cancer, led to a significant role in the percentage of diagnosed men with early stage (Bener et al., 2008).

Here, we tried to highlight the prevalence of prostate cancer in our province, clarified possible risk factors for disease occurrence, and to increase awareness about this disease.

\section{MATERIALS AND METHOD}

This is a single-centre study that was carried out during the period from July 2018 to March 2019 in Al-Shifaa Oncology Center in Al-Sadder Teaching Hospital at Misan province in which 53 male patients, documented with prostatic cancer, from different Iraqi cities. The data was collected depending on the available resources including the patient's history and investigation focusing on the following variables: age (ranging from 49-86 years), address, smoking, the patient comorbidities (including hypertension and diabetes mellitus), family history of prostatic cancer, family history of other cancer, histopathology, stages on the available Gleason score we divided the patient into three categories (welldifferentiated $\leq 6$; moderately differentiated $=7$; poorly 
differentiated $\geq 8$ ) and lastly PSA(ng/ml) level divided into 4 categories $(<10,10-20,20-100,>100)$.

Table1. All criteria of prostate cancer

\begin{tabular}{|c|c|c|}
\hline $\begin{array}{l}\text { Age group } \\
\text { (years) }\end{array}$ & No & $\%$ \\
\hline$<50$ & 1 & 1.88 \\
\hline $50-59$ & 7 & 13.2 \\
\hline $60-69$ & 15 & 28.3 \\
\hline $70-79$ & 21 & 39.62 \\
\hline $80-89$ & 9 & 16.98 \\
\hline$>89$ & $\mathrm{O}$ & $\mathrm{O}$ \\
\hline Total & 53 & 100 \\
\hline \multicolumn{3}{|c|}{ Tobacco habit } \\
\hline Smoking & 35 & 66.03 \\
\hline Non-smoking & 19 & 33.95 \\
\hline Total & 53 & 100 \\
\hline \multicolumn{3}{|c|}{ Family history } \\
\hline Positive & 3 & 5.66 \\
\hline Negative & 50 & 94.33 \\
\hline Total & 53 & 100 \\
\hline \multicolumn{3}{|c|}{ Family history of other cancer types } \\
\hline Positive & 7 & 13.2 \\
\hline Negative & 46 & 86.79 \\
\hline Total & 53 & 100 \\
\hline \multicolumn{3}{|c|}{ Diabetes mellitus } \\
\hline Yes & 17 & 32.07 \\
\hline No & 36 & 67.92 \\
\hline Total & 53 & 100 \\
\hline \multicolumn{3}{|c|}{ Hypertension } \\
\hline Yes & 37 & 69.81 \\
\hline No & 16 & 30.18 \\
\hline Total & 53 & 100 \\
\hline \multicolumn{3}{|c|}{ Gleason's score } \\
\hline$\leq 6$ & 8 & 15.09 \\
\hline 7 & 15 & 28.3 \\
\hline$\geq 8$ & 30 & 56.6 \\
\hline Total & 53 & 100 \\
\hline \multicolumn{3}{|c|}{ PSA level ng/mL } \\
\hline$<10$ & 1 & 1.88 \\
\hline $10-20$ & 4 & 7.54 \\
\hline $20-100$ & 7 & 13.2 \\
\hline$>100$ & 41 & 77.35 \\
\hline Total & 53 & 100 \\
\hline
\end{tabular}

\section{RESULT AND} DISCUSSION

A total of 53 patients were included in this study, regarding age 1 patients were younger than 50 years and 9 patients between (80-90) years with the rest distributed in between these ages. Among 53 persons, 35 of the participants were a smoker, and 19 of the participants were a non-smoker. As for the family history of prostate cancer, 3 patients had a positive family history, while 50 patients had a negative family history. As for the family history of prostate cancer, 7 patients had a positive family history, while 46 patients had a negative family history. A total number of patients were 53, where 37 patients had hypertension, while 16 patients were nonhypertensive. As for diabetes mellitus, we found that 17 patients had diabetes, while 36 patients had no diabetes. Regarding the histopathology, we discovered that all the patients had adenocarcinoma. Regarding the grading of cancer, we found that from 53 patients, 30 patients had had high-grade Gleason score (poorly differentiated). In comparison, only 8 patients had low-grade score (welldifferentiated), with the remaining patients falling between them. Regarding the prostatic specific antigen (PSA), we found that 41 patients had PSA level $>100$, while only 1 patient had PSA <10, with the remaining patients falling between these ranges.

In our study we found the disease start to be prevalent after the age of 50 years and reaching a peak among patients between (70-80) years with median age 71 years, this is consistent with other studies done in Iran (Fitzmaurice $e t$ al., 2017), and Asia nations (American Cancer Society, 2019); however, in Turkey in 2012 a study found the incidence rate was determined to be highest between the ages of 75 and 79 years (Fitzmaurice et al., 2017). In the USA a study found that approximately one-third were aged 55-64 years, one third aged between 65-75, and nearly one-fourth of all men diagnosed were aged 75 years or older, and the median age at diagnosis was 70 years (Fitzmaurice et al., 2017).

Smoking associated with aggressive tumour features and worse outcomes (Mosli, 2003), and we found most of the patients were a smoker. Singapore Chinese prostatic men non-smoker in about 42\% (Harold, 2018), while in our study, $35.8 \%$ of patients were a non-smoker. Another study in Turkey reported $44.8 \%$ were non- smoker (Frederrick et al., 2009).

Several studies have confirmed family history as a risk factor of prostate cancer (Bener et al., 2008; Collin et al., 2009), in our study there is $5.6 \%$ of the participants had a positive family history, and they were from the first-degree relative, which is close to $6.8 \%$ was observed in a Swiss study (Kimura and Egawa, 2018), this is consistent with the documented data that $5-10 \%$ of prostate cancer had a positive family history.

In more than one study done to look for the association between prostate cancer and other cancer, it is well known that the family history of breast cancer, increase the risk for 
development of prostate cancer (Zorlu et al., 2014; Brawley et al., 2012; Brookman-May et al., 2018; Watters et al., 2009; Butler et al., 2009). In our study, we found that $13.2 \%$ had a family history of different types of cancer, of these patients about $1 / 3$ had a family history of breast cancer. The link between the two cancers was found to be present in previous studies (Zorlu et al., 2014; Frank et al., 2014; Jimenez Mendoza et al., 2018).

Many previous studies suggested there is an association between hypertension and the development of prostate cancer and formulated a common androgen-mediated mechanism (Bruner et al., 2003). We found that $69.8 \%$ of patients were hypertensive, which may occur due to most of the patients were elderly, where many comorbidities associated with prostate cancer seen in a higher age population. In the previous study recorded that diabetes mellitus reduces the risk of prostate cancer (Frank et al., 2017; Rodriguez et al., 1998). In our study, 32\% of patients had diabetes, whereas, in the USA, they found that only $21.6 \%$ had diabetes (Frank et al., 2017).

In our study, we found more than half of patients had highgrade cancer (Gleason score $\geq 8$ ), in contrast to a study done in UAE in 2016 showed, Score of $\geq 8$ in $24 \%$ (Frank et al., 2017). Low-grade, Gleason score (2-6) was found in a study done in the USA in $46.3 \%$ since the widespread use of PSA screening has lowered the median age at diagnosis and increased the number of men diagnosed with localised disease (Brandt et al., 2012). Another study in Turkey at 2014 showed that Gleason score was $\leq 6$ in $49.1 \%, 7$ in $27.8 \%$ and $>7$ in $20.6 \%$ of the cases, where the most common Gleason score is 6 and less (Martin et al., 2010), while in our study only $15 \%$ diagnosed with Gleason score $\leq 6$.

An elevated serum PSA level is one of the most important features suggestive of prostate cancer (Shah and Vladimir, 2017; Liang et al., 2016), in a Korean study it was found that higher level of PSA makes the diagnosis of prostate cancer more accurate, when PSA $>100(\mathrm{ng} / \mathrm{ml})$, all the patient will have advanced prostate cancer (Pakzad et al., 2016). We found $77.35 \%$ of patients had PSA level $>100 \mathrm{ng} / \mathrm{ml}$, this finding when correlated with other findings that the higher percentage had high-grade cancer (poorly differentiated) so these patients are more likely to have metastatic disease to lymph node and distant organ. This goes with what Jeffrey $H$. Reese, a urologist at Santa Clara Valley Medical Center (SCVMC) in California, who presented the results of his study at the Annual Meeting of the American Urological Association, where he confirmed that poor survival and significant morbidity in men who had been initially presented with PSA $\geq 100 \mathrm{ng} / \mathrm{mL}$ (Pakzad et al., 2016).

\section{CONCLUSION}

The prostate cancer in Misan appears to be more likely to occur in the presence of certain risk factor including age, hypertension, family history of prostate cancer and breast cancer at least, and less likely in the presence of diabetes mellitus. The prostate cancer is more likely to be presented with high grade and metastatic disease, and this may be primarily explained by the absence of the screening program in Misan, and partly due to the delay in the diagnosis in the early stages of the disease, in addition to the decrease in the awareness about the disease among the population.

\section{REFERENCES}

American Cancer Society 2019, Cancer Facts and Figures, Atlanta, 2019.

Bener, A, Ayub, H, Kakil, R \& Ibrahim, W 2008, 'Patterns of cancer incidence among the population of Qatar: a worldwide comparative study', Asian Pac J Cancer Prev, vol. 9, pp. 19-24.

Brandt, A, Sundquist, J \& Hemminki, K 2012, 'Risk for incident and fatal prostate cancer in men with a family history of any incident and fatal cancer', Annals of Oncology, vol. 23, no. 1, pp. 251-256.

Brawley, OW 2012, 'Trends in Prostate Cancer in the United States', JNCI Monographs, vol. 45, pp. 252-256.

Bray, F, Ferlay, J, Soerjomataram, I., et al. 2018, 'Global Cancer Statistics 2018: GLOBOCAN Estimates of Incidence and Mortality Worldwide for 36 Cancers in 185 Countries', Ca Cancer J Clin, vol. 68, pp. 394-424. 
Brookman-May, S., et al. 2018, 'Latest Evidence on the Impact of Smoking, Sports, and Sexual Activity as Modifiable Lifestyle Risk Factors for Prostate Cancer Incidence, Recurrence, and Progression: A Systematic Review of the Literature by the European Association of Urology Section of Oncological Urology (ESOU)', Eur Urol Focus, 02, 007.

Bruner, DW, et al. 2003, 'Relative risk of prostate cancer for men with affected relatives: systematic review and metanalysis', Int J Cancer, vol. 107, pp. 797-803.

Butler, LM, et al. 2009, 'Cigarette smoking and risk of prostate cancer among Singapore Chinese', Cancer Causes Control, vol. 20, no. 10, pp. 1967-1974.

Collin, SM, Metcalfe, C, Donovan, JL, et al. 2009, 'Associations of sexual dysfunction symptoms with PSAdetected localised and advanced prostate cancer: a casecontrol study nested within the UK population-based ProtecT (Prostate testing for cancer and Treatment) study', Eur J Cancer, vol. 45, no. 18, pp. 3254-61.

Frederick, O, Stephens, K, Aigner, R 2009, Basics of Oncology, Germany, Springer, p. 237.

Fitzmaurice, C, Allen, C, Barber, R 2017, 'Global, regional, and national cancer incidence, mortality, years of life lost, years lived with disability, and disability-adjusted life-years for 32 cancer groups, 1990 to 2015', JAMA Oncol., vol. 3 p. 524.

Frank, C, Fallah, M, Ji, J, Sundquist, J, Hemminki, K 2014, 'The population impact of familial cancer, a major cause of cancer', Int J Cancer., vol. 134, no. 8, pp. 1899-1906.

Frank, C, Sundquist, J, Hemminki, A, Hemminki, K 2017, 'Familial Associations Between Prostate Cancer and Other Cancers', Eur Urol., vol. 71, no. 2, pp. 162-165.

Harold, ET 2018, 'Global Trends and Prostate Cancer A Review of Incidence, Detection and Mortality as Influenced by Race, Ethnicity, and Geographical location', American Journal of Men's Health, vol. 12, no. 6, pp. 1807-1823.

Jiménez-Mendoza, E, et al. 2018, 'Smoking and prostate cancer: a life course analysis', BMC Cancer, vol. 18, p. 160.

Kimura, T, Egawa, S 2018, 'Epidemiology of prostate cancer in Asian countries', International Journal of Urology, vol. 25, pp. 524-531.

Kimura, T, Takahashi, H, Okayasu, M, et al. 2016, 'Time trends in histological features of latent prostate cancer in Japan', J. Urol., vol. 195, pp. 1415-1420.

Liang, Z, et al. 2016, 'Hypertension and risk of prostate cancer: a systematic review and meta-analysis', Sci Rep., vol. 11 , no. 6,31358 .
Martin, RM, Vatten, L, Gunnell, D \& Romundstad, P 2010, 'Blood pressure and risk of prostate cancer: Cohort Norway (CONOR)', Cancer Causes Control, vol. 21, pp. 463-472.

Mosli, HA 2003, 'Prostate cancer in Saudi Arabia in 2002', Saudi Med J., vol. 24, pp. 573-581.

Pakzad, R, et al. 2016, 'Prostate Cancer in Iran: Trends in Incidence and Morphological and Epidemiological Characteristics', Asian Pac J Cancer Prev, vol. 17, no. 2, pp. 839-843.

Rodriguez, C, Calle, EE, Tatham, LM, Wingo, PA, MiracleMcMahill, HL, Thun, MJ \& Heath, CW 1998, 'Family history of breast cancer as a predictor for fatal prostate cancer', Epidemiology, vol. 9, no. 5, pp. 525-529.

Shah, N \& Vladimir, I 2017, 'The association between hypertension and prostate cancer', Rev Urol., vol. 19, no. 2, pp. 113-118.

Watters, JL, Park, Y, Hollenbeck, A, et al. 2009, 'Cigarette smoking and prostate cancer in a prospective US cohort study', Cancer Epidemiol Biomarkers Prev., vol. 18, pp. 2427-2435.

Zorlu, F et al. 2014, 'An Epidemiological Study of Prostate Cancer Incidence in Turkey', APJCP., vol. 15, no. 21, pp. 9125-9130. 